\title{
Geo-Electrical Survey for Assessing Aquifer Characteristics and Groundwater Potential in Eshtehard Plain, Iran
}

\author{
${ }^{1}$ Leila Khodapanah, ${ }^{2}$ Alireza Dizaji, ${ }^{3}$ Nasrin Khodapanah and ${ }^{4}$ Masoud Saatsaz \\ ${ }^{1}$ Department of Geosciences, Faculty of Geosciences and Petroleum Engineering, \\ Universiti Teknologi (Petronas), 32610 Seri Iskandar, Perak, Malaysia \\ ${ }^{2}$ Water Resources Researches Office, Tehran Regional Water Authority, Hijab St., \\ Keshavarz Blvd, Tehran, Iran \\ ${ }^{3}$ Faculty of Engineering Technology, Universiti Malaysia Pahang (UMP), Lebuhraya Tun Razak, \\ 26300 Gambang, Kuantan, Pahang, Malaysia \\ ${ }^{4}$ Institute for Advanced Studies in Basic Sciences (IASBS), Prof. Yousef Sobouti Blvd,
} 45195-1159 Zanjan, Iran

\begin{abstract}
The Eshtehard Plain in Tehran Province, Iran has been investigated by Vertical Electrical Soundings (VES) using the Schlumberger array in order to determine the aquifer characteristics and groundwater potential of the subsurface layers. The main goals of this survey were to determine the aquifer parameters such as thickness, depth, aquifer type and boundaries and high yield potential zones. For those purposes 65 VES's with maximum $1000 \mathrm{~m}$ current electrode separation were conducted within the area. Four main geo-electrical layers were identified by correlation of interpreted VES data with some existing boreholes. The results were presented in the form of resistivity, aquifer thickness and Transverse Resistance (RT) maps. According to, the thickness map, average thickness of the alluvial aquifer ranges between 50 and $175 \mathrm{~m}$. The zones with maximum transverse resistance (1000-2000 ohm $\left.\mathrm{m}^{2}\right)$ in south of Eshtehard city and west of the plain represent the areas with highest degree of quality and quantity of groundwater.
\end{abstract}

Key words: Groundwater, geo-electrical sounding, aquifer characteristics, hydrogeological parameters, resistivity, Iran

\section{INTRODUCTION}

The Eshtehard Plain located in south western part of Tehran Province is considered as one of the promising areas for industrial and agricultural developments in the Tehran Province. It is sited between $35^{\circ} 34^{\prime}$ and $35^{\circ} 47^{\prime}$ north and $50^{\circ} 10^{\prime}$ and $50^{\circ} 47^{\prime}$ east (Fig. 1). Average elevation of the plain is $1220 \mathrm{~m}$ above sea level and the average annual precipitation is $227 \mathrm{~mm}$. The climate of the area is characterized by dry and cold winters and dry and warm summers. The floodways from the southern highs are in the south-north direction and supply the water for the plain. The Shoor River intersects the north-western edge of the area, running from west to east and leaves the plain near Ja'far Abad village (Fig. 2). According to the chemical analysis data of the river water in Tehran Regional Water Authority, the average Electrical

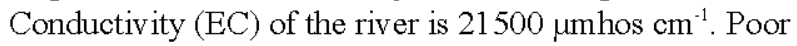
quality of the river water causes contamination of the sources of subterranean flows in Eshtehard Plain. The southern elevated areas include Kurds, Siah Kamar, Gara Guni, Goosh Guni, Gande Guyu mountains while Halghe Dar crest is the peak of the northern part.

Clean water supply is one of the most important key factor of sustainable development in every country even in those countries with highest average annual precipitation (Theeba et al., 2015). It is more critical in arid and semiarid areas like Eshtehard for socio-economic development, healthy ecosystems and human survival. Groundwater resources play an important role for the water supply of Eshtehard Plain. Lack of sufficient surface water had caused water consumers to rely on groundwater for more than $95 \%$ of their needs (Anonymous, 2006). Unbalance sequence between demand and supply of water resources due to drought, rapid population growth and agricultural development coupled with pollution through human and industrial activities are the important factors on increasing water resources crisis in the study area. These factors are similar to those which have affected other groundwater

Corresponding Author: Nasrin Khodapanah, Faculty of Engineering Technology, Universiti Malaysia Pahang (UMP), Lebuhraya Tun Razak, 26300 Gambang, Kuantan, Pahang, Malaysia 


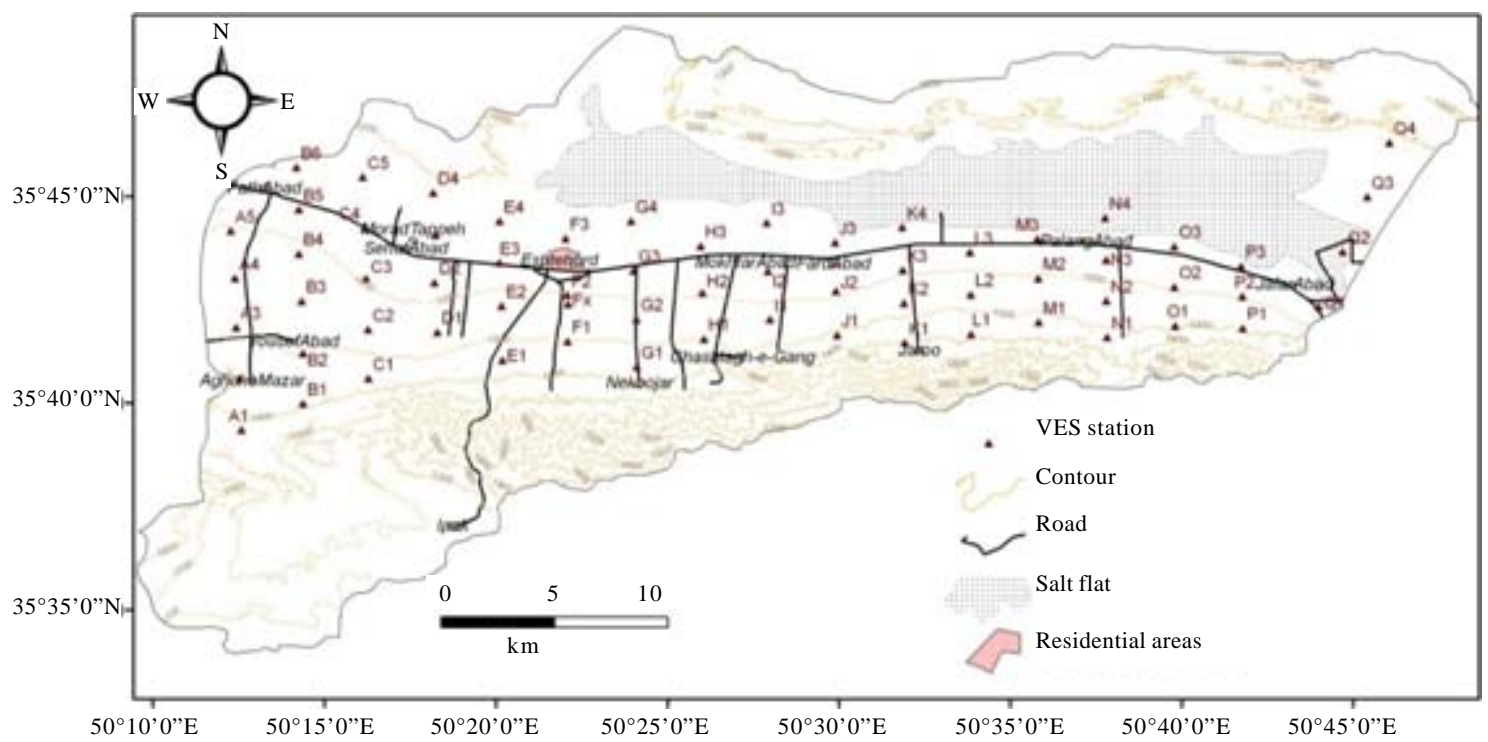

Fig. 1: Location map of study area and geo-electrical soundings

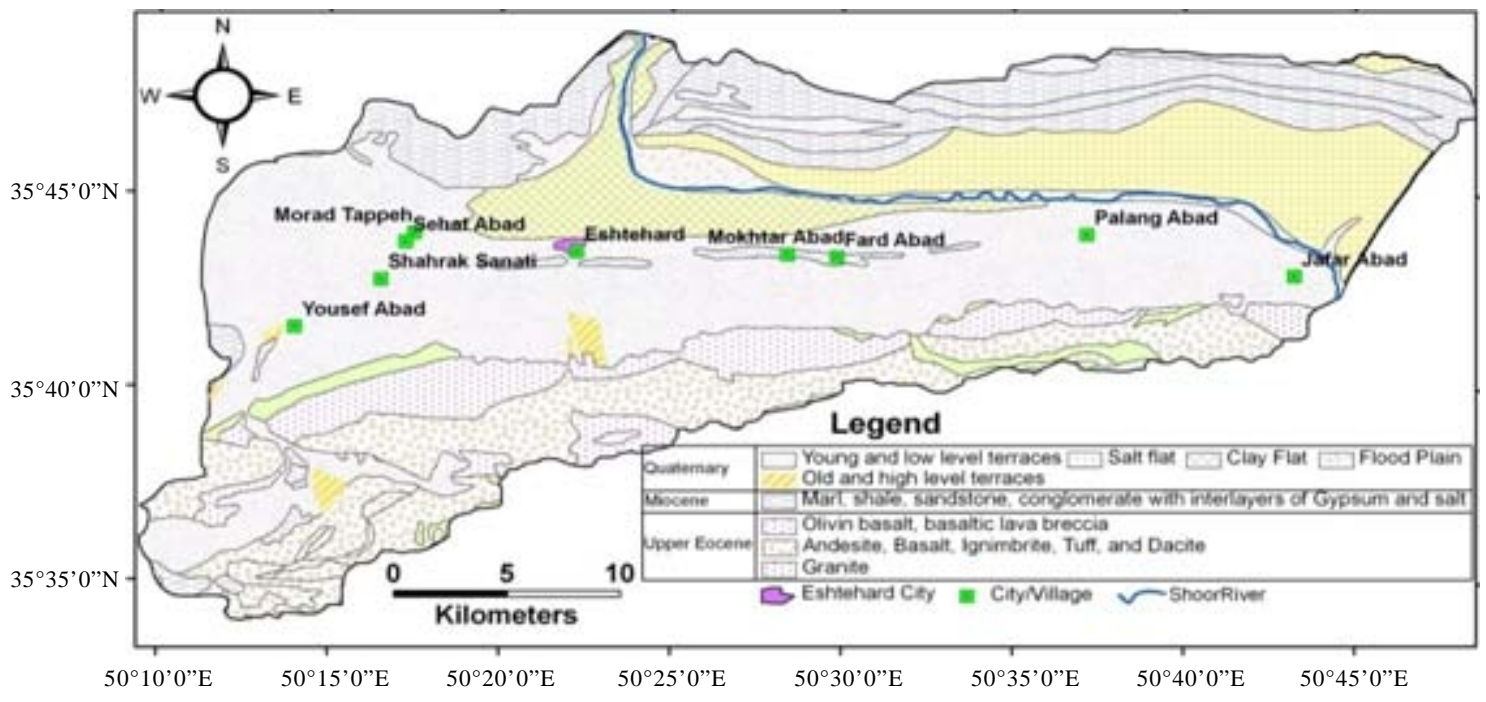

Fig. 2: Geological map of the study area

resources in adjacent alluvial aquifer in Tehran Province (Khodapanah et al., 2011). Hence, proper identification and delineation of the groundwater resources is essential for the water resources management in the study area. In this regard, geophysical surveys and especially the geo-electrical methods are generally considered as practical tools to obtain more accurate information about subsurface aquifer conditions including geometrical characteristics, aquifer type and depth of materials (consolidated or unconsolidated), depth of weathered or fractured zones, depth to groundwater, depth to bedrock and salt content of groundwater. Literature about groundwater exploration using geophysical techniques have been reported throughout the world (Mbonu et al., 1991; Ibrahim et al., 1994; Nowroozi et al., 1999; Lashkaripour, 2003; Radulescu et al., 2006). Over the past three decades, the application of geophysical survey had increased significantly in the geological, hydrogeological and hydrochemical studies. Since, the and of 1990's, several geophysical survey methods were subsequently developed to assess the water bearing layers in the subsurface. The majority of these studies have focused on assessments of aquifer properties and only few attempts have been made to assess groundwater quality and potential pollution at the aquifer scale. However, because of growing evidence that the quality of the 
subsurface environment is being adversely affected by human activities and increase in public concern, the focus point of Iranian researchers has recently shifted from water quantity issues to qualitative studies issues (Fig. 1 and 2).

In this study, resistivity data and interpretation of geo-electrical surveys have been used to delineate the geometry of aquifer including boundaries, subsurface disposition, thickness of alluvial deposits, type and the depth to top of the bedrock and finally to assess the quantity of groundwater based on correlation between available data. Such studies are extremely useful for water resource management, policy, decision-making, short and long-term plans, programs and projects in the context of consumption management, aquifer development, sustainability strategies and quality control.

\section{MATERIALS AND METHODS}

Geology of the study area: The Eshtehard plain is a part of syncline formed by North Tehran Thrust and is located between Central Alborz Unit and Central Iran Unit (Zadeh, 2002). It is surrounded on both sides by the elevated areas consisting of Miocene formation in north and Eocene formation in south (Fig. 2). The stratigraphic sequence from base to top is outlined by Eocene to Miocene outcrops, Pliocene to Quaternary and Quaternary deposits. According to geological map produced by Geological Survey of Iran these formations are categorized as follows.

Eocene formations: The Eocene formations are widespread in the Southern Highs and generally consist of volcanic and pyroclastic rock. The lithology of these formations is regularly from andesite, basalt, ignimbrite, tuff and dacite which in some parts are affected by tectonic phenomena such as faulting.

Miocene formations: The Northern Highs (Halghe Dar) are made of the deposits of Miocene era. In addition, these alluvial deposits form the Southern Highs of profiles a-c (Fig. 1). The lithology of Miocene formations is normally from marl, shale, sandstone, conglomerate with inter-layers of gypsum and salt. These formations play the role of bedrock for the alluvial deposits and act as one of the contamination source of subterranean flows. Miocene formations of the Northern Highs are affected by thrust faulting in west-east direction.

Plio-quaternary formations: The lithology of this formation is consist of unconsolidated conglomerate with inter-layers of sandstone, silt and argillite which outcrop at the edges of the south-western elevated area (between the profiles a-b; Fig. 1). This formation can contain subterranean water flow based on information derived from dugout wells in the area.

Quaternary deposits: The Quaternary deposits which cover the plain area are composed mainly of old alluvial terraces, alluvial fans, clay and salt flats. These deposits constitute the main aquifer of Eshtehard.

Geoelectrical resistivity survey: The Vertical Electrical Sounding (VES) technique which measures the electrical resistivity variation with depth is one of the most popular and worldwide applied techniques for groundwater studies. Generally, the electrical resistivity of a rock formation varies according to the aquifer lithology, porosity, pore size and shape, salinity and water content. Hence, there are no sharp limits for electrical resistivity of porous formations. The resistivity of rock and soil is determined by the amount of mineral-conducting constituents and the content of more or less mineralized water in the pore's interstices. The latter item is nearly the most dominant factor. In fact, most rocks and soils are conductors for electric current principally due to the presence of internally contained water. The widely differing resistivity of the various types of impregnating water (meteoric water, sea water) alone can cause variations in the resistivity of rocks (sedimentary and igneous). This can range from a few tenths of an ohm $\mathrm{m}$ to hundreds of ohm m. This is the reason why the geo-electric resistivity method is the most useful geophysical method in groundwater prospecting.

Large variety of groundwater problems have been resolved by using geo-electrical resistivity techniques. Some examples include determination of depth, thickness and boundary of aquifers (Lashkaripour, 2003; Zohdy and Jackson, 1969), porosity, transmissivity and hydraulic conductivity of aquifers (Chandra et al., 2008; Ghaib, 2009), groundwater quality (Radulescu et al., 2006), tectonic effect on groundwater occurrence (Mohamaden et al., 2009), aquifer vulnerability (Omosuyi et al., 2007), saline water intrusion (Choudhury et al., 2001) and contamination of groundwater (Karlik and Kaya, 2001).

Data interpretation: A total of 65 Vertical Electrical Sounding (VES) points were measured along 17 profiles in north-south directions. Figure 1 shows the location of electrical profiles and sounding stations. To ensure a penetration of up to $250 \mathrm{~m}$, a maximum current electrode separation $(\mathrm{AB})$ of $1000 \mathrm{~m}$ was used. The standard Schlumberger configuration was applied utilizing the 
Resistivity Meter WDDS-1 to carry out this study. Coordinates were measured by a Global Positioning System (GPS-Garmin). Eleven of the VES points were conducted adjacent to nearby existing boreholes for correlation purposes. The apparent resistivity values were then plotted on transparent double log graph paper and thus, sounding curves were produced. The field curves were interpreted by the well-known method of curve matching with the aid of IPI2Win v.2.1 Software. A reliable meaningful interpretation can be made when additional subsurface information preferably lithological borehole data are available. Therefore, initial estimates of the resistivity and thickness of the various geo-electric layers at each VES location were calibrated with lithological borehole data and geological information.
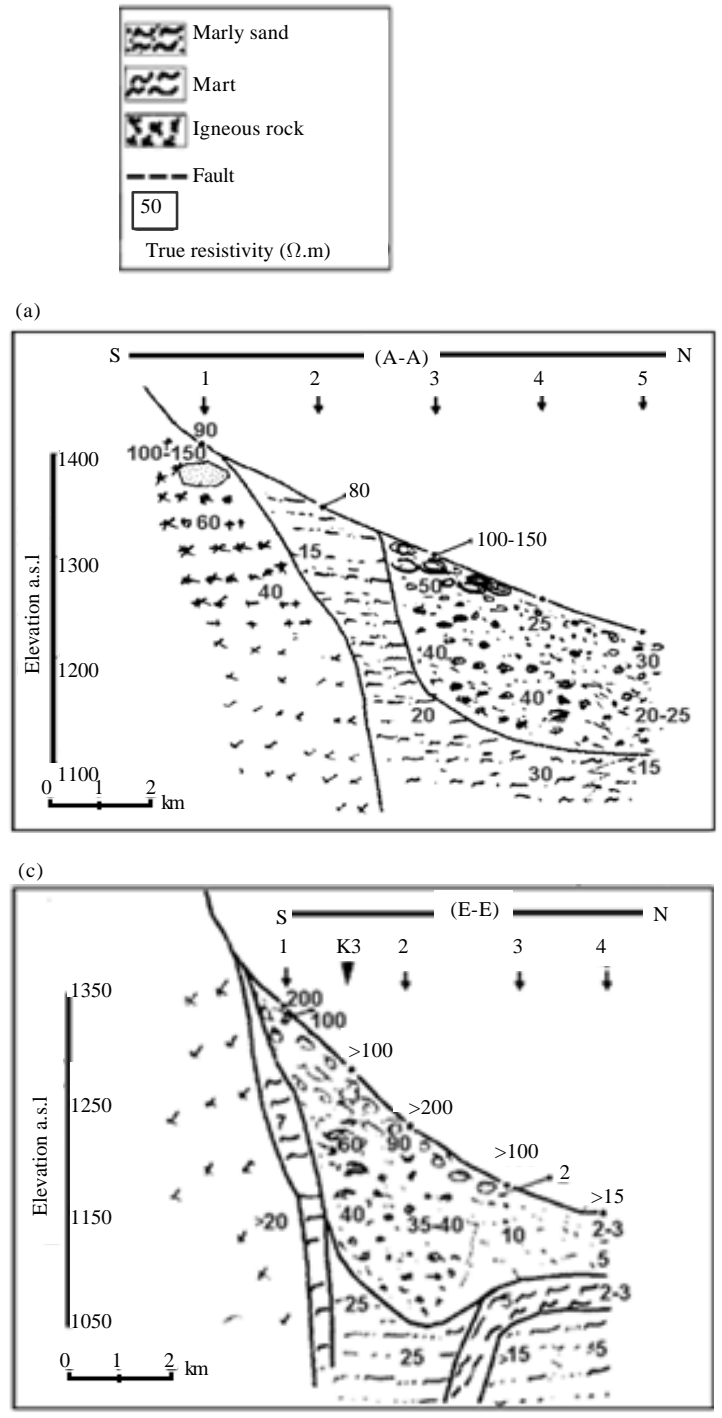

\section{RESULTS AND DISCUSSION}

Geo-electric sections, maps of iso-apparent resistivity is opach of aquifer thickness, depth to top of bedrock and transverse resistivity contour maps were determined based on the interpretation of sounding data. According to, geo-electric sections (Fig. 3) interpretation in the vicinity of available boreholes, the following main geo-electric layers were identified to be associated main geologic layers:

- Quaternary Alluvial deposits (in some cases more than one layer was evident in this zone but these cases were also treated as single layers for better identification)
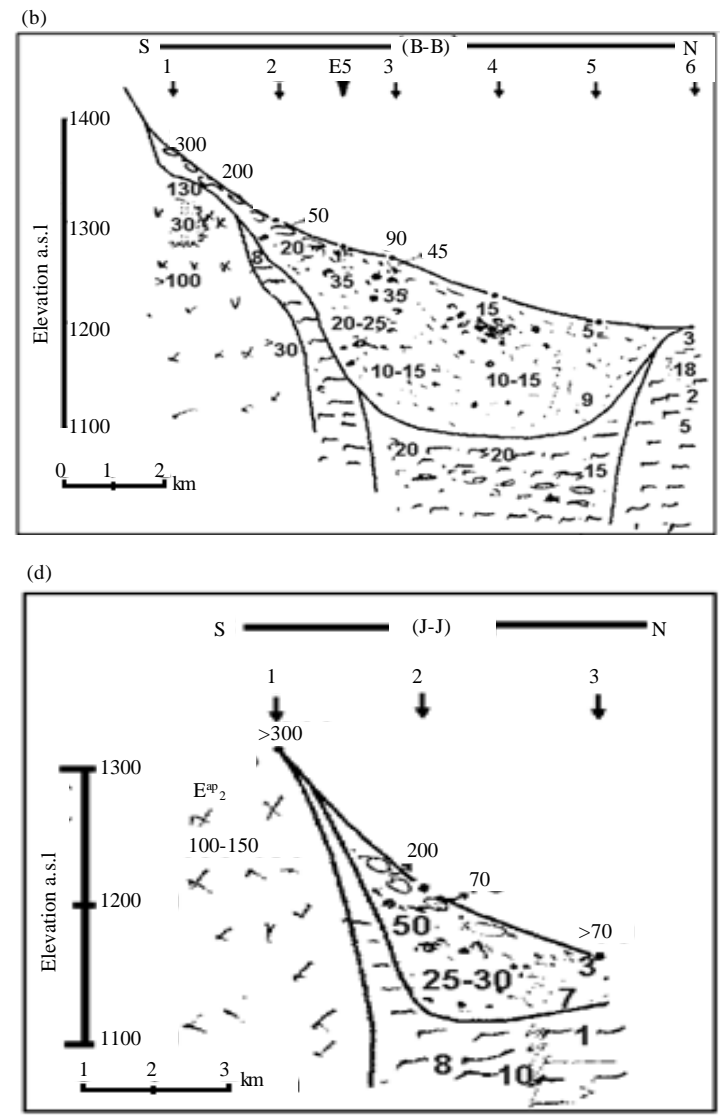

Fig. 3: Continue 

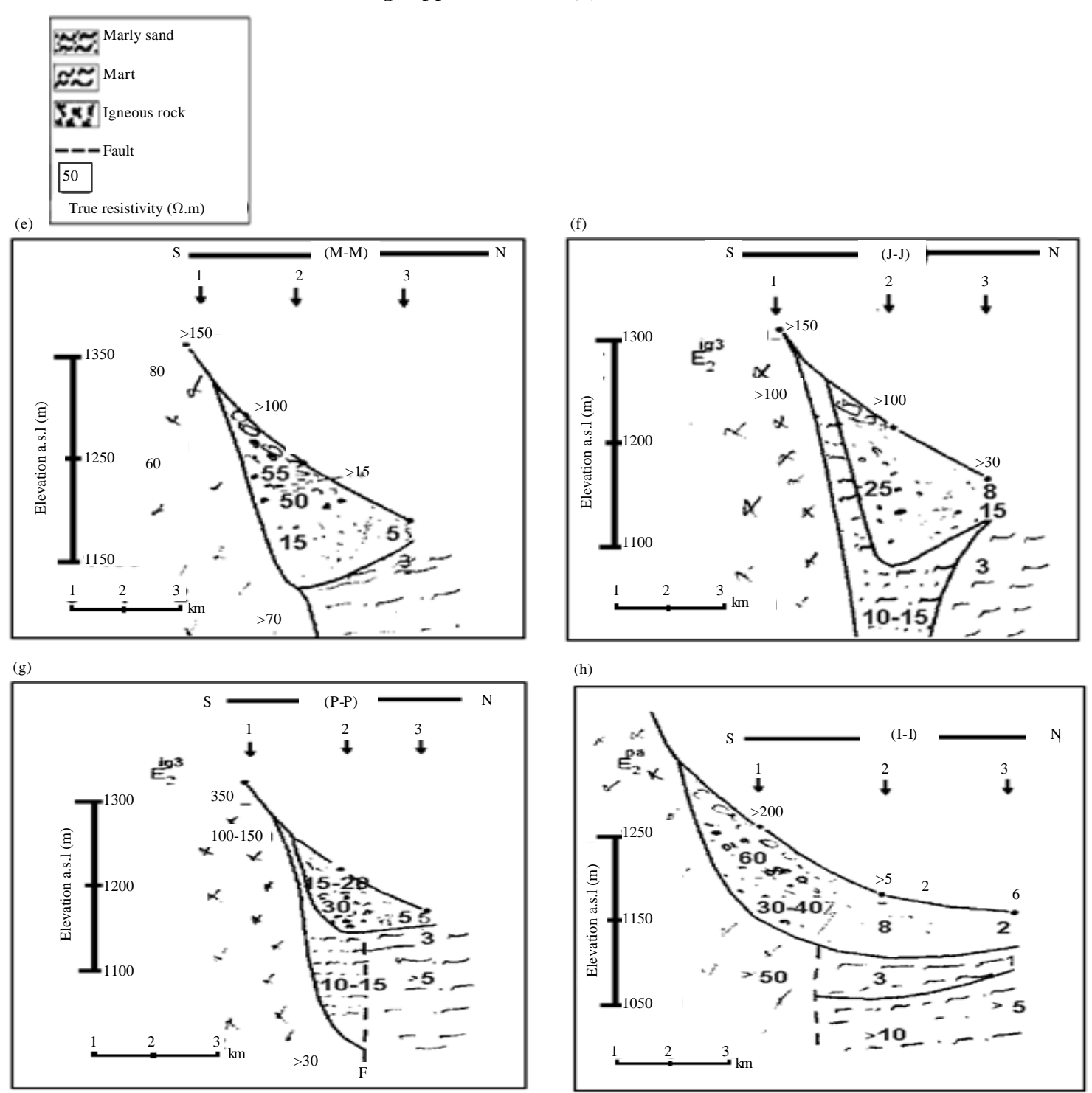

Fig. 3: Selected geo-electric sections across Eshtehard Plain

Table 1: Correlation of resistivity and geo-electric layers in the study area Geo-electric layer

Coarse-grained and dry alluvium Resistivity range (ohm m) $70>300$

$30-65$

$10<<70$

$10<30$

Medium to fine-grained and water bearing alluvium

Fine-grained alluvium containing relatively saline water or clay minerals

Conglomerate, sandstone, silt and clay

$2-<10$

$10-\sim 40$

$<1-8$

$5->15$

Andesite, basalt, ignimbrite, tuff and dacite

$20>200$

Vertical electric sounding sample E2

$\mathrm{E} 2$

M2

K3

$\mathrm{J} 3$

A2

B6 $\mathrm{K} 1$

- Pliocene formation consisting of conglomerate, sandstone, silt and clay

- Miocene formations (generally consisting of marl)

- Eocene formations (volcanic and pyroclastic)

Average resistivity values of the different geo-electrical layers identified in the study area are shown in Table 1.

Iso-apparent resistivity contours: In order to assess the lateral apparent resistivity over a horizontal plane at a 


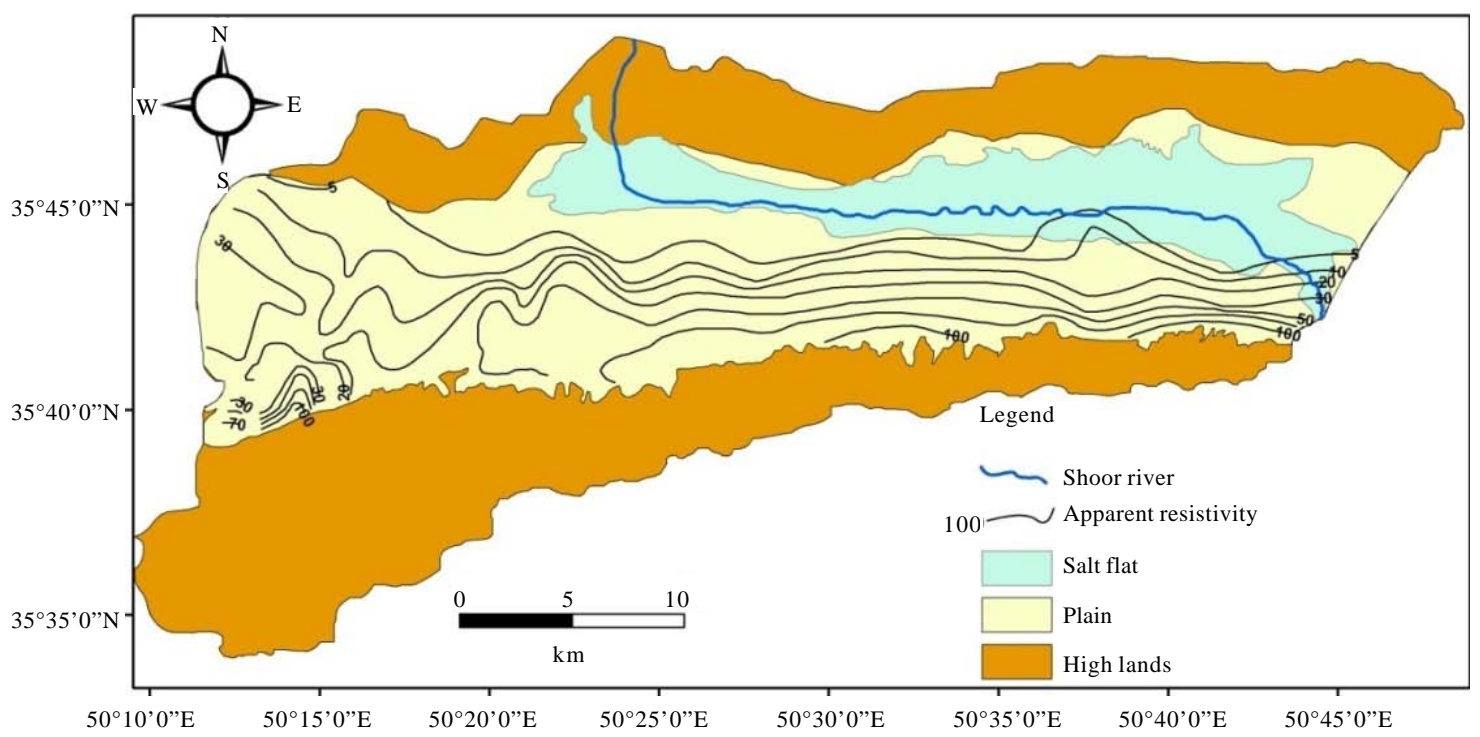

Fig. 4: Iso-apparent resistivity map for $\mathrm{AB}=140 \mathrm{~m}$

certain depth, the iso-apparent resistivity maps were drawn for maximum current electrode separation (AB) of 140,300 and $640 \mathrm{~m}$. Below are the descriptions of each map.

Iso-apparent resistivity map for $\mathbf{A B}=140$ : This map which shows the resistivity down to the depth of about $35 \mathrm{~m}$, has been mostly prepared for analyzing the granulation of the alluvial deposits (Fig. 4). The variation in resistivity is between $5 \mathrm{ohm} \mathrm{m}$ in northern parts to $100 \mathrm{ohm} \mathrm{m}$ in southern heights. It shows the alluvial fans deposition from the edge of the southern highs to the north. This clearly indicates the decrease of grain size and increase of conductive mineral content from the edge of the southern heights to the central and northern parts. The areas with apparent resistivity below $10 \mathrm{ohm} \mathrm{m}$ are made of fine-grain silt to clay alluviums containing partially to totally salt waters that the intensity of conductive salts and saltiness increase in the zones of $5 \mathrm{ohm} \mathrm{m}$ as below:

A zone with the resistivity of $50 \mathrm{ohm} \mathrm{m}$ in the vicinity of the soundings: E2, F1, Fx, F2 and G2 describes the most significant deposition zone in the study area. The alluvium of relatively coarse-grain with appropriate permeability has been formed in this area. The second noticeable deposit zone is in vicinity of soundings: B3, A3-A5 with resistivity values ranging from 30 to about $50 \mathrm{ohm} \mathrm{m}$. The alluvium of this zone is relatively medium-grained to coarse-grained. Volcanic and pyroclastic rocks of Eocene formation are responsible for the increase of resistivity at the sounding points of $\mathrm{Al}$, $\mathrm{B} 1, \mathrm{~J} 1, \mathrm{~K} 1, \mathrm{~L} 1, \mathrm{M1}, \mathrm{N1}, \mathrm{O} 1, \mathrm{P} 1$ and Q1. On the other hand, the decrease of the resistivity at the sounding locations of A2 is attributed to Marly deposits of Miocene.
Iso-apparent resistivity map for $\mathbf{A B}=\mathbf{3 0 0}$ : This map provides the assessment of the water bearing strata and to shows the overall apparent resistivity at a depth of $75 \mathrm{~m}$ shown in Fig. 5 .

A zone with the resistivity of $30-50 \mathrm{ohm} \mathrm{m}$ in the vicinity of the soundings: $\mathrm{E} 2, \mathrm{~F} 1, \mathrm{Fx}, \mathrm{F} 2$ and $\mathrm{G} 2$ are attributed to the deposition of medium to coarse grained alluvium at these locations. Deposition of medium-grained alluvium in soundings: A3 and A4 have a resistivity for this area of up to $30 \mathrm{ohm} \mathrm{m}$.

The two areas above have good permeability compared to other parts of the plain. The Alluvial fan sedimentation from edge of Southern heights toward north is obvious in this map too, as the resistivity decreases from South to North. Brackish to relatively brackish water has caused the resistivity decreases to $<10 \mathrm{ohm} \mathrm{m}$ in some areas which are also characterized with low permeability. Resistivity of $<5 \mathrm{ohm} \mathrm{m}$ is attributed to clay deposits with saline water and Miocene bedrock. Increase of resistivity from $50-150 \mathrm{ohm} \mathrm{m}$ in southern heights is due to volcanic and pyroclastic formations of Eocene. Overall, the apparent resistivity values in this map (iso-apparent resistivity map with $\mathrm{AB}=300 \mathrm{~m}$ ) are lower than the previous map (iso-apparent resistivity map with $\mathrm{AB}=140 \mathrm{~m}$ ) due to presence of more salts in pore water or a decrease of grain size or both with increase in the depth of investigation.

Iso-apparent resistivity map for $\mathbf{A B}=\mathbf{6 4 0}$ : This map which shows the overall apparent resistivity at adepth of $160 \mathrm{~m}$ can be used to assess the bedrock in most areas of the Eshtehard Plain (Fig. 6). In this map, the resistivity 


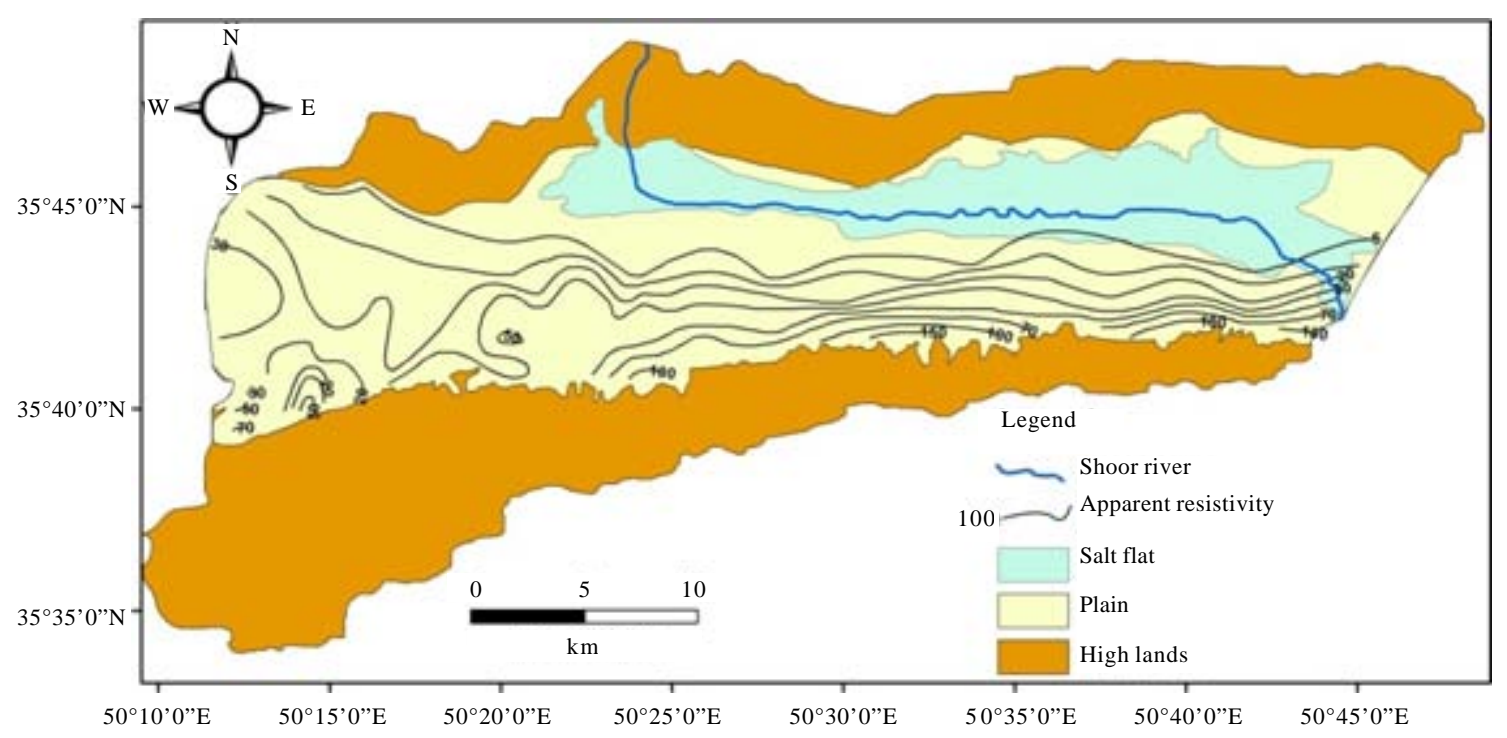

Fig. 5: Iso-apparent resistivity map for $\mathrm{AB}=300 \mathrm{~m}$

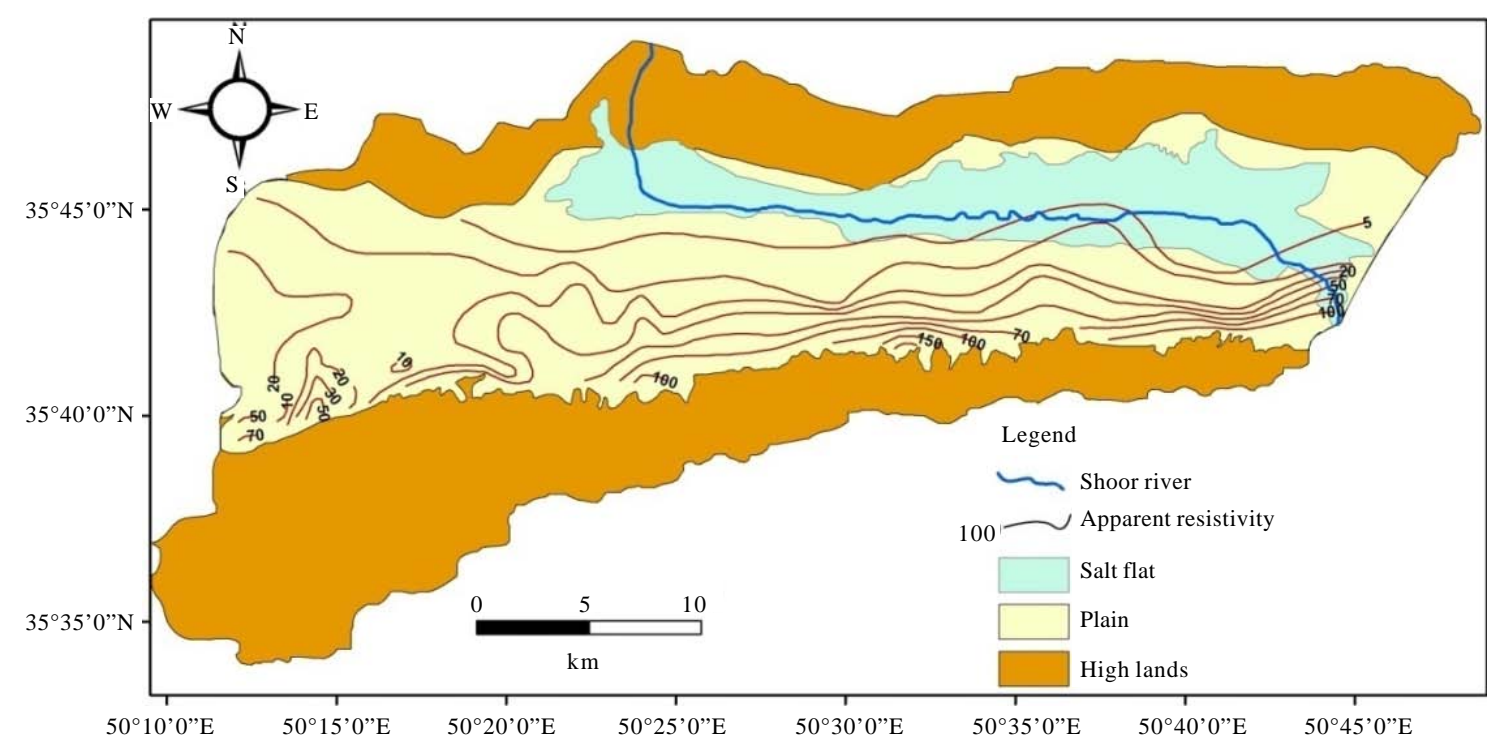

Fig. 6: Iso-apparent resistivity map for $\mathrm{AB}=640 \mathrm{~m}$

values have significantly decreased compared to other maps in most parts of plain. It proves the effect of marly formations of Miocene and Pliocene which is a conductive bedrock. Areas with resistivity between 50 to more than $200 \mathrm{ohm} \mathrm{m}$ are attributed to volcanic and pyroclastic formations of Eocene which extend towards the northern parts and in these areas are replaced by Miocene and Pliocene formations which are connected to more conductive minerals.

Comparison between the iso-resistivity maps (Fig. 4-6) and iso-conductivity map (Fig. 7) shows some similarities. The iso-conductivity map indicates an increasing trend from Southern parts towards the north and eastern parts along with groundwater flow path. On the other hand, the interpretation of iso-resistivity map shows a decreasing trend from southern parts towards north. This indicates an increase in salts concentrations that is associated with a decrease in rock resistivity and increase in conductivity. In order to interpret the aquifer resistivity in term of water quality, the formation factor should be assumed constant in the study area (Ibrahim et al., 1994). Since, this assumption is not valid 


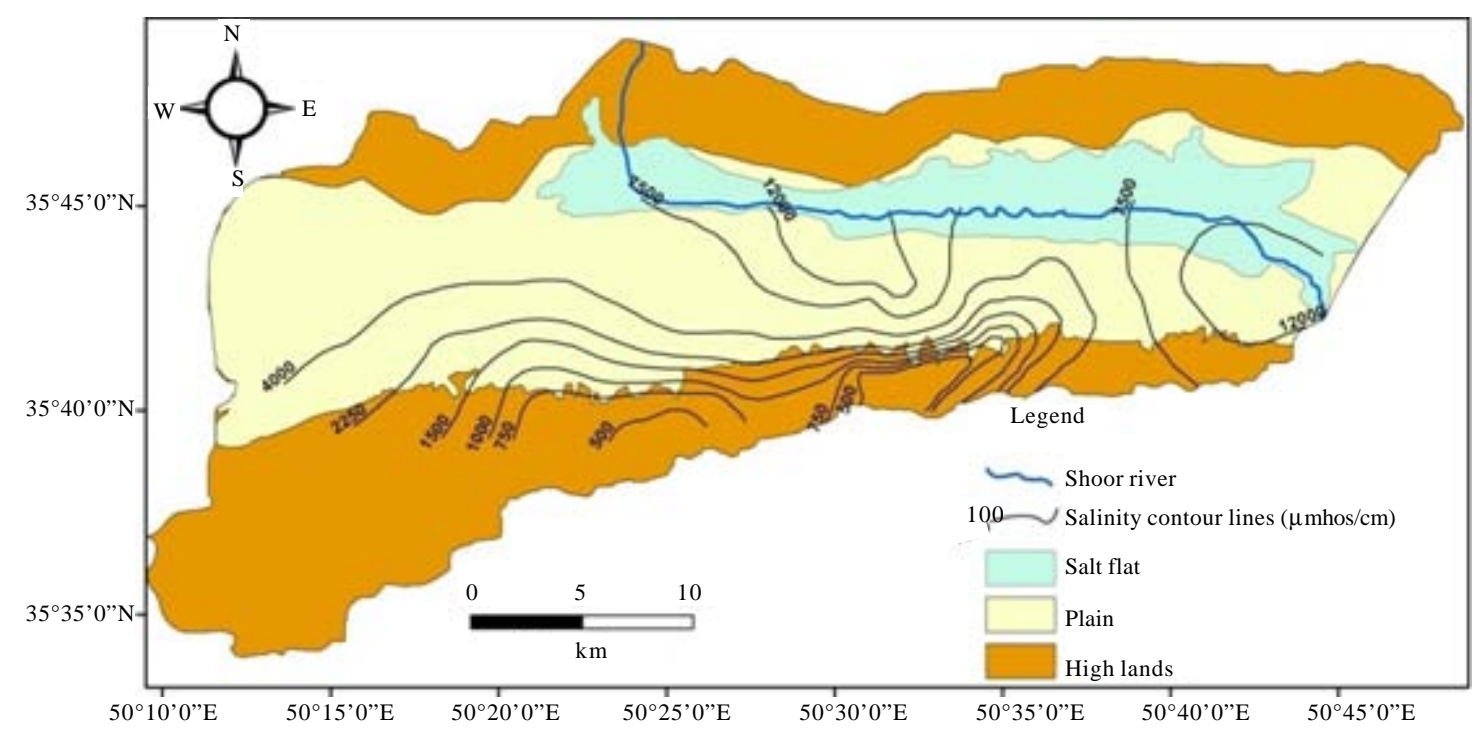

Fig. 7: A contour map showing groundwater salinity of Eshtehard aquifer

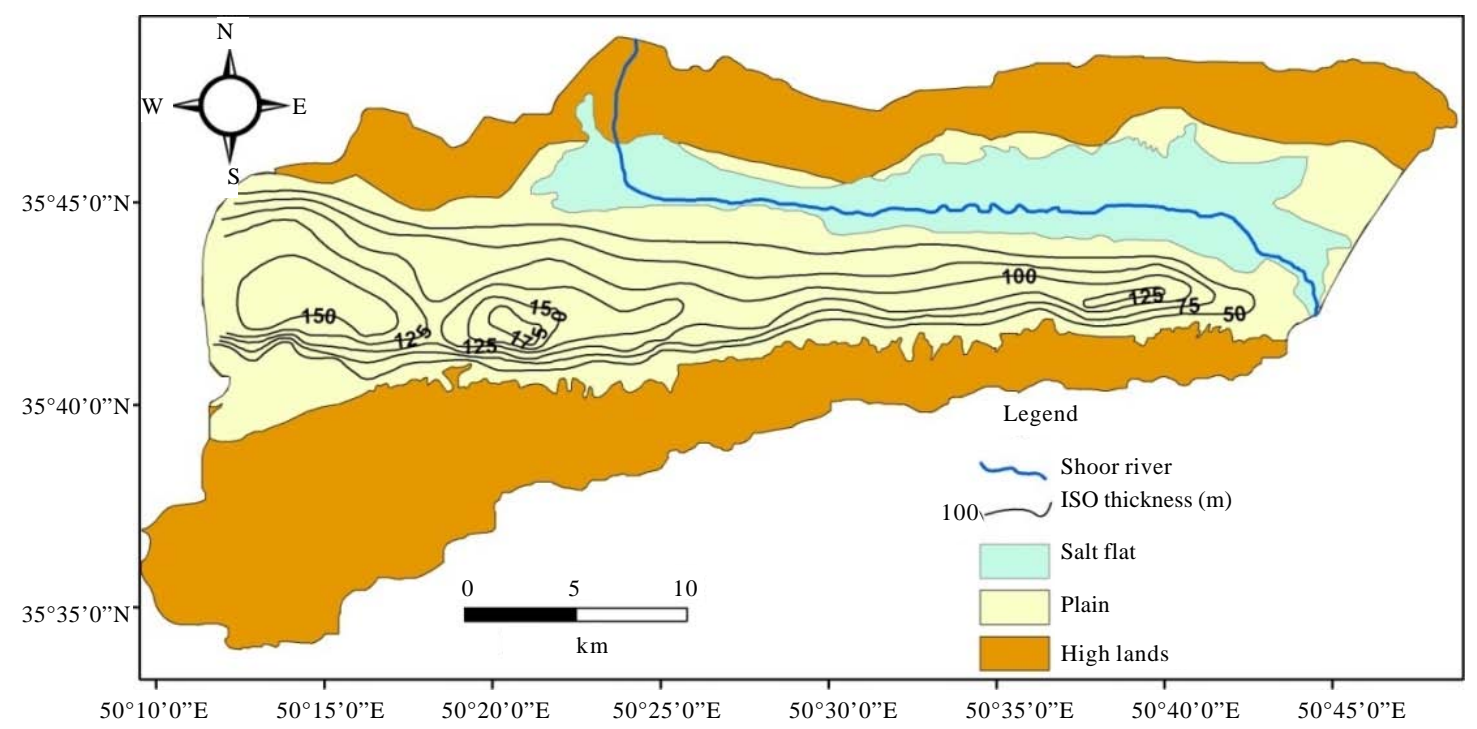

Fig. 8: A map showing Isopach thickness of alluvial deposits

in the study area, the lower resistivity in the northern parts was probably due to both poor water quality and finer materials of sand and silty clay.

Isopach map of alluvial deposits thickness: Based on interpretation of VES soundings, the isopach map of alluvial deposits thickness was prepared (Fig. 8). According to this map, the thickness of alluvial deposits is highly variable across the study area and ranges between $<50 \mathrm{~m}$ at the periphery of the study area to more than $175 \mathrm{~m}$ in southwest of Eshtehard City (in the vicinity of sounding E2 and F2). Tectonic phenomena most probably had a great role on the origin of deep alluvial deposits with thickness more than $150 \mathrm{~m}$ around soundings A4, B3, B4, C2 and E2.

Isopach map of elevation of top of bedrock: This map displays elevation contours of the upper surface of the bedrock in the study area (Fig. 9). As the bedrock has steep inclines (especially volcanic and pyroclastic Eocene formations), the elevation contours have been drawn in $25 \mathrm{~m}$ intervals. Based on this map, the inclination of volcanic and pyroclastic formations are steep and extend towards the north direction. The lowest elevation of 


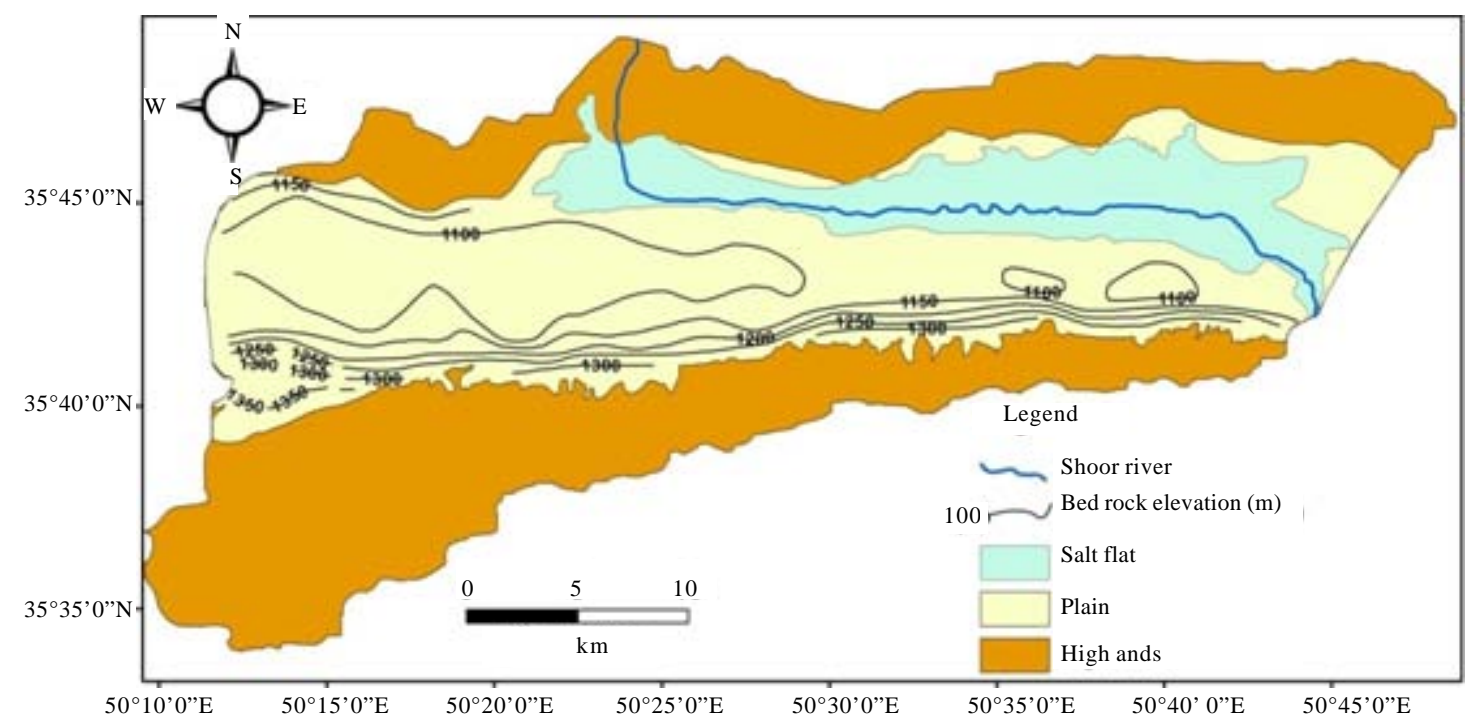

Fig. 9: A map showing Isopach elevation of alluvial deposits at top of bedrock

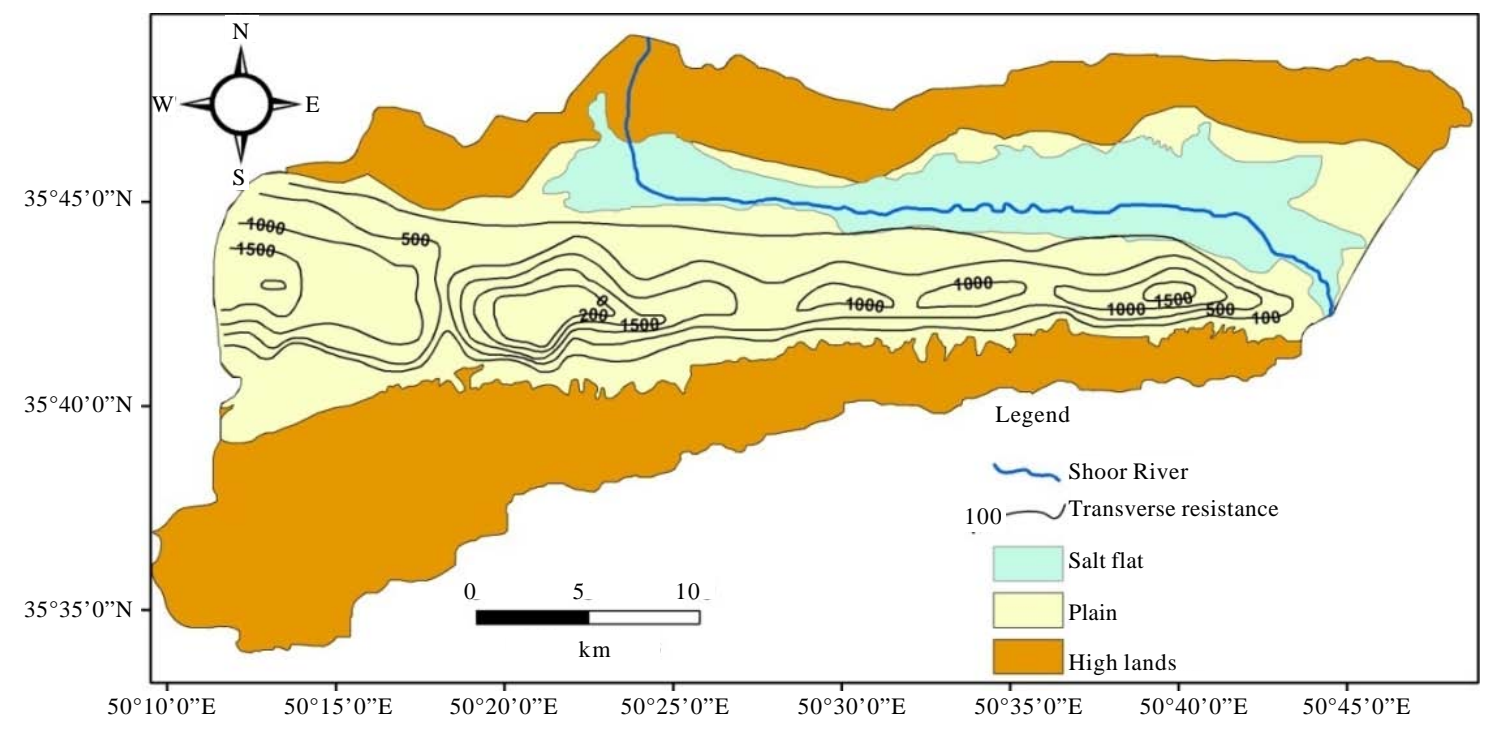

Fig. 10: Isopach map of transverse resistance

bedrock is $<1100 \mathrm{~m}$ in the central parts. Towards the north and south, the elevation of bedrock increases until the periphery of the plain at which the bedrock has outcrops. The steep incline of bedrock (Eocene formation) in the South of the present study area confirms the effect of tectonic activities.

Isopach map of transverse resistance: In order to determine the actual cause of the anomalies and whether they are due to chemical changes or thickness, transverse resistance map of the aquifer is produced. (Fig. 10). Such maps generally reflect the change in one or a combination of factors such as thickness, clay content or salinity. It should be noted that RT map show the potential of the aquifer for water resources and quality in the study area (Nejad, 2009; Toto et al., 2008). Zones with maximum transverse resistance are the best location for future development of the aquifer. Although, in Eshtehard Plain RT map shows low potential of aquifer from quantitative to qualitative point of view.

The best quality and quantity of groundwater sources are found in vicinity of soundings of $\mathrm{E} 2, \mathrm{~F} 2, \mathrm{Fx}$, G2, J2, L2, N2, O2, A4, A5, B3, B4, C2 and C3 with transverse resistance ranges between 1000-2000 ohm m$~_{2}$. 
The RT values decreases towards the periphery of the plain where it reaches a value of $1<100 \mathrm{ohm} \mathrm{m}^{2}$. Decrease of the saturation zone thickness in the southern area is the reason for the decrease in RT value while in the northern parts it is due to decrease of grain size and increase in salinity.

The areas with transverse resistance value between $500-<1000 \mathrm{ohm} \mathrm{m}$ in various parts of the plain are in the second place of significance from quantity and quality point of view. The areas with transverse resistance about $<100 \mathrm{ohm} \mathrm{m}^{2}$ which appeared in the edges of the northern and the southern elevated areas of the plain has no hydrological significance and groundwater potential.

\section{CONCLUSION}

The results of geo-electrical investigation of Eshtehard Plain were used to evaluate the subsurface hydrogeological conditions to a depth of about $250 \mathrm{~m}$. Based on the interpretation of geo-electrical data, the following conclusions are drawn.

Alluvial fans are deposited in the direction from the southern elevated areas to the northern part of the plain. The deposits have been extended more or less in the north-south direction. In the southern to middle parts of the plain, the alluvial deposits with medium-grained to coarse-grained material with less salts have been deposited while in the northern part silt and clay alluvium containing higher conductive salts have been developed. The bedrock of the edges in the southern elevated areas are made of volcanic and pyroclastic formations whereas in the central to the northern parts are made from Pliocene and Miocene formations which have more conductivity than the upper alluviums deposits.

Based on the geo-electrical sections, the maximum thickness of alluvial deposits in Eshtehard Plain is estimated to be approximately $185 \mathrm{~m}$ that can be explained by the effects of tectonic activities. According to, the thickness map, the average thickness of the alluvial aquifer ranges between $<50 \mathrm{~m}$ to more than $175 \mathrm{~m}$.

In the map of transverse resistance, the areas with RT values from 1000-2000 ohm m $\mathrm{m}^{2}$ represent the area with best water quality and quantity of groundwater sources. A deep zone in the central-Southern part of the plain that expands in the west-east direction is identified. As a conclusion, the limited groundwater resources with suitable quality and quantity are threatened by the presence of marly deposits of Miocene and Shoor River (with very high EC) in the northern part. In order to avoid the intrusion of saline water from the northern fronts toward the south and consequently, contamination of the groundwater resources, future development of the groundwater resources needs an integrated groundwater management policy. Restriction of groundwater abstraction within Eshtehard area is an urgent issue.

\section{ACKNOWLEDGEMENT}

This study is funded by UMP grant RDU-1703283. The researchers would like to thank the Tehran Regional Water Authority for their technical assistance and support in this project.

\section{REFERENCES}

Anonymous, 2006. Annual survey database for groundwater resources. Iran Water Resources Management Company, Tehran, Iran.

Chandra, S., S. Ahmed, A. Ram and B. Dewandel, 2008. Estimation of hard rock aquifers hydraulic conductivity from Geoelectrical measurements: A theoretical development with field application. J. Hydrol., 357: 218-227.

Choudhury, K., D.K. Saha and P. Chakraborty, 2001. Geophysical study for saline water intrusion in a coastal alluvial terrain. J. Applied Geophys., 46: 189-200.

Ghaib, F.A., 2009. The assessment of erbil aquifer using geo-electrical investigation (Iraqi Kurdistan Region). J. Appl. Sci. Environ. Sanitation, 4: 43-54.

Ibrahim, K.E., M.T. Hussein and N.G. Adam, 1994. Geoelectric measurements for Qroundwater assessment in Gedaref area, Sudan. Earth Sci., 7: 27-39.

Karlik, G. and M.A. Kaya, 2001. Investigation of groundwater contamination using electric and electromagnetic methods at an open waste-disposal site: A case study from Isparta, Turkey. Environ. Geol., 40: 725-731.

Khodapanah, L., W.N.A. Sulaiman and H.R. Nassery, 2011. Hydrogeological framework and groundwater balance of a semi-arid aquifer, a case study from Iran. J. Water Resour. Prot., 3: 513-521.

Lashkaripour, G.R., 2003. An investigation of groundwater condition by geoelectrical resistivity method: A case study in Korin aquifer, southeast Iran. J. Spatial Hydrol., Vol. 3,

Mbonu, P., J. Ebeniro, C. Ofoegbu and A. Ekine, 1991. Geoelectric sounding for the determination of aquifer characteristics in parts of the Umuahia area of Nigeria. Geophysics, 56: 284-291. 
Mohamaden, M.I., 2009. Geoelectrical survey for groundwater exploration at the Asyuit Governorate, Nile Valley, Egypt. Mar. Sci., 20: 91-108.

Nejad, H.T., 2009. Geoelectric investigation of the aquifer characteristics and groundwater potential in Beli ball an Azad University Farm, Khuzestan Province, Iran. J. Appl. Sci., 9: 3691-3698.

Nowroozi, A.A., S.B. Horrocks and P. Henderson, 1999. Saltwater intrusion into the freshwater aquifer in the Eastern shore of Virginia: A reconnaissance electrical resistivity survey. J. Applied Geophys., 42: $1-22$.

Omosuyi, G.O., J.S. Ojo and M.O. Olorunfemi, 2007. Geoelectric sounding to delineate shallow aquifers in the coastal plain sands of Okitipupa Area, Southwestern Nigeria. Online J. Earth Sci., 1: 170-179.
Radulescu, V., F. Radulescu and I. Stan, 2006. Geoelectrical measurement applied to the assessment of water quality. Geoelectrical Meas. Appl. Assess. Groundwater Qual., 1: 107-110.

Theeba, M.R., G.K. Easther, W.K. Toh, Q.L. Foo and P.C. Lee et al., 2015. Pilot study on development of mobile water treatment system for flood Prone Area. Intl. J. Eng. Technol. Sci., 4: 57-68.

Toto, E.A., C. Kerrouri, L. Zouhri, M.E. Basri and A. Ibenbrahim et al., 2008. Geoelectrical exploration for groundwater in Al Maha Forest, Ain Jouhra, Morocco. Hydrol. Processes Intl. J., 22: 1675-1686.

Zadeh, D., 2002. Geology of Iran. Amirkabir Publication, Tehran, Iran, Pages: 600.

Zohdy, A.A. and D.B. Jackson, 1969. Application of deep electrical soundings for groundwater exploration in Hawaii. Geophys., 34: 584-600. 